\title{
Acute Hyponatremia following Hypotonic Intravenous Fluid in a 4-year-old Child
}

\author{
${ }^{1}$ Preeti Rustagi, ${ }^{2}$ Naina P Dalvi, ${ }^{3}$ Bharti A Tendolkar, ${ }^{4}$ Suhas Kotak
}

\begin{abstract}
Hyponatremia is the most frequently encountered electrolyte disorder in hospitalized patients. It develops due to either surplus water or decreased sodium in the extracellular fluid. In children, the source of excess water is frequently the administration of hypotonic intravenous fluids. The current recommendations of hypotonic maintenance fluids may be appropriate for a healthy child, but may not apply to hospitalized children who are more likely to have a nonosmotic stimulus for antidiuretic hormone (ADH) production, such as anxiety, stress, pain, etc. Fall in plasma sodium concentration acutely to $<130 \mathrm{mmol} / \mathrm{L}$ leads to brain cell swelling and devastating neurological outcome. Previous studies have reported the potential harm with these solutions and the need to reconsider their routine use in children. We present a case report of 4 -year-old child, admitted with head injury and normal CT brain, who developed hyponatremic convulsions following administration of Isolyte-P as maintenance fluid as per standard guidelines.
\end{abstract}

Keywords: Hyponatremia, Hypotonic intravenous fluid, Nonosmotic stimulus for antidiuretic hormone.

How to cite this article: Rustagi P, Dalvi NP, Tendolkar BA, Kotak S. Acute Hyponatremia following Hypotonic Intravenous Fluid in a 4-year-old. Res Inno in Anesth 2016;1(2):63-64.

Source of support: Nil

Conflict of interest: None

\section{INTRODUCTION}

Hyponatremia, defined as a serum sodium $<135$ meq/L, is the most common electrolyte disturbance seen in pediatric patients. It develops either due to deficit of sodium or due to excess of water, latter being more common. The usage of hypotonic parental fluids like Isolyte-P in hospitalized pediatric population, who often have nonosmotic stimulus for antidiuretic hormone (ADH) can result in water excess, thereby leading to hyponatremia

\footnotetext{
${ }^{1}$ Assistant Professor, ${ }^{2}$ Additional Professor, ${ }^{3}$ Professor and Head, ${ }^{4}$ Ex-Resident

${ }^{1,3,4}$ Department of Anesthesia, Lokmanya Tilak Municipal General Hospital and Lokmanya Tilak Municipal Medical College, Mumbai, Maharashtra, India

${ }^{2}$ Department of Anesthesia, HBT Medical College and Dr RN Cooper Municipal General Hospital, Mumbai, Maharashtra, India

Corresponding Author: Preeti Rustagi, Assistant Professor Department of Anesthesia, Lokmanya Tilak Municipal General Hospital and Lokmanya Tilak Municipal Medical College Mumbai, Maharashtra, India, Phone: +919769215359, e-mail: drpreetirustagi@rediffmail.com
}

and its neurologic complications. We discuss a case of 4-year-old child who developed hyponatremic convulsions following administration of Isolyte-P for 24 hours as maintenance fluid.

\section{CASE REPORT}

A 4-year-old female child weighing $12 \mathrm{~kg}$ was brought to trauma ward with alleged history of fall from height of about 10 feet, 8 hours back. She gave history of three episodes of vomiting. Other history, such as loss of consciousness/convulsions/ENT bleed/chest, or abdominal trauma was not present. On examination, she was conscious, oriented, and her modified Glasgow coma scale was 15/15. Computed tomography (CT) scan of brain was found to be normal. The patient was transferred to pediatric ward for observation, where she was started on intravenous Isolyte-P 20 mL/hour, inj. Taxim, and inj. Tramadol.

After 26 hours, her level of consciousness deteriorated with Glasgow coma scale E1 M3 V2. The patient had repeated episodes of convulsions. She was intubated, put on mechanical ventilatory support, and started on anticonvulsants but her convulsion was refractory to standard anticonvulsant treatment. Repeat CT-BRAIN was done with a suspicion of development of some lesion giving rise to posttraumatic epilepsy, but it was again unremarkable. Meanwhile, her investigations revealed serum sodium $118 \mathrm{meq} / \mathrm{L}$. She was immediately started on intravenous $3 \% \mathrm{NaCl}$ at the rate of $12 \mathrm{~mL} /$ hour for first 4 hours and then $6 \mathrm{~mL} /$ hour for next 4 hours. Her convulsions resided and the level of consciousness improved. We could extubate the patient on the same day. Serum sodium levels were repeated every 2 hours. Investigations after 24 hours revealed serum sodium $128 \mathrm{meq} / \mathrm{L}$. The patient was discharged after 2 days.

\section{DISCUSSION}

Hyponatremia, defined as a serum sodium concentration less than $135 \mathrm{meq} / \mathrm{L}$, is the most common electrolyte disturbance seen in pediatric patients. ${ }^{1}$ Acute hyponatremia is defined as hyponatremia that develops in less than 48 hours. It can be fatal for both children and adults; however, children are more vulnerable to the effects of fluid and electrolyte imbalance. Conditions like primary kidney disease which have disproportionate loss of 
sodium or conditions where the ability of the kidneys to conserve sodium is affected can lead to hyponatremia. Disproportionate gain of electrolyte-free water in the vascular compartment also leads to dilutional hyponatremia or water intoxication. The increased ratio of free water to sodium in the vascular space will cause the water to move from this extracellular compartment into the intracellular compartment until osmolality is equalized, leading to cellular edema.

In hospitalized children, this disproportionate gain of electrolyte free water often results from hypotonic intravenous fluids used in maintenance therapy. The current recommendation for the amount of maintenance fluid is based on caloric expenditure data in healthy children at rest. To meet the daily sodium and potassium requirements of 3 and $2 \mathrm{mmol} / \mathrm{kg}$ respectively, maintenance electrolytes were calculated from that delivered by the same amount of human milk. This combination of maintenance fluid requirements and electrolyte requirements results in a hypotonic solution. ${ }^{2}$ Whereas, these recommendations may be appropriate for the healthy child, they may not apply to hospitalized children, who are much more likely to have a nonosmotic stimulus for ADH production, such as anxiety, stress, pain, nausea, etc. ${ }^{3}$

Moritz and Ayus ${ }^{4}$ reevaluated the factors used to calculate water and electrolyte requirements in Holliday and Segar's article and pointed out that the original calculations did not consider the unpredictable effect of nonosmotic stimuli for ADH secretion in the acutely ill child. Those with meningitis, encephalitis, or head injury are at risk for excessive ADH secretion. Burrows et $\mathrm{al}^{5}$ compared hypotonic with isotonic intravenous fluids in children who underwent surgery for scoliosis. Both groups had a fall in their sodium levels in the postoperative period, but the reduction was greater in those who received the hypotonic solution. Anesthetic agents, pain, nausea, and opiates are also associated with nonosmotic $\mathrm{ADH}$ secretion, and contribute to the development of hyponatremia in these children. ${ }^{6}$

The presence of nonosmotic stimulus for release of pain, anxiety, etc. could not be ruled out in our patient. Since ADH makes the latter parts of the distal nephron permeable to water, there will be very little excretion of electrolyte-free water in such cases. ${ }^{7}$ Administration of hypotonic maintenance fluid only adds to the problem. Hoorn ${ }^{8}$ in an observational study also had reached a similar conclusion.
Many investigators have compared isotonic solutions with the standard hypotonic maintenance therapy. In a randomized trial of different fluid protocols in children

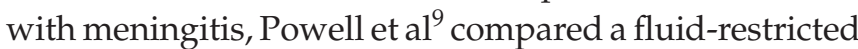
group who received hypotonic saline with a fluid-deficit replacement plus maintenance regimen using predominantly isotonic solutions. Children in the isotonic group received an average of $6 \mathrm{mmol}\left[\mathrm{Na}^{+}\right] / \mathrm{kg} /$ day and had normal sodium levels, whereas those in the hypotonic group received an average of $2 \mathrm{mmol}\left[\mathrm{Na}^{+}\right] / \mathrm{kg} /$ day and became hyponatremic.

Choong et $\mathrm{al}^{7}$ concluded that the chance of developing hyponatremia is 17.2 times higher following administration of hypotonic solutions than isotonic fluids.

With the administration of isotonic saline, development of hypernatremia and hyperchloremic metabolic acidosis is a concern, but none of the studies strongly support this. Therefore, in pediatric patients, while hypotonic solutions exacerbate the risks of hyponatremia, isotonic solutions may be protective.

\section{REFERENCES}

1. Farrell C, Rio MD. Hyponatremia. Pediatr Rev 2007 Nov 1;28(11):426-428.

2. Murat I, Dubois MC. Perioperative fluid therapy in paediatrics. Pediatr Anesth 2008 May;18(5):363-370.

3. Halperin ML, Shafiee MA, Bohn D, Hoorn EJ. How to select optimal maintenance intravenous fluid therapy. Q J Med 2003 Aug;96(8):601-610.

4. Moritz ML, Ayus JC. Hospital-acquired hyponatremia - why are hypotonic parenteral fluids still being used? Nat Clin Pract Nephrol 2007 Jul;3(7):374-382.

5. Burrows FA, Shutack JG, Crone RK. Inappropriate secretion of antidiuretic hormone in a postsurgical pediatric population. Crit Care Med 1983 Jul;11(7):527-531.

6. Skippen P, Adderley R, Bennett M, Cogswell A, Froese N, Seear M, Wensley D. Iatrogenic hyponatremia in hospitalized children: can it be avoided? Paediatr Child Health 2008 Jul;13(6):502-506.

7. Choong K, Kho ME, Menon K, Bohn D. Hypotonic versus isotonic saline in hospitalised children: a systematic review. Arch Dis Child 2006 Oct;91(10):828-835.

8. Hoorn EJ. Acute hyponatremia related to intravenous fluid administration in hospitalized children: an observational study. Pediatrics 2004 May;113(5):1279-1284.

9. Powell KR, Sugarman LI, Eskenazi AE, Woodin KA, Kays MA, McCormick KL, Miller ME, Sladek CD. Normalization of plasma arginine vasopressin concentrations when children with meningitis are given maintenance plus replacement fluid therapy. J Pediatr 1990 Oct;117(4):515-522. 